\title{
Método e metafísica: Descartes entre as Regras e as Meditações
}

\author{
Marco Antonio Valentim \\ Universidade Federal do Paraná \\ mavalentim@yahoo.com.br
}

resumo 0 propósito deste artigo é o de discutir em linhas gerais a relação entre método e metafísia na filosof ia de Descartes. Pretendemos fazê-lo media nte a cont raposição das Meditações de filosofia primeira às Regras para a direção do espírito quanto a alguns temas em comum. Nosso objetivo principal é questio nar o papel desempenhado pela evidência intelectual no cont exto epistemológico das Regras e no cont exto metafísico das Medi tações. Retoma ndo, num prime i ro momento, algumas interpretações sobre o assunto e discutindo, num segundo momento, a natureza da dúvida e a noção de evidênc ia nas Meditações, procuramos concluir com a sugestão de que no sistema cartesia no tem lugar um conflito de ordem estrutural entre método e metafísica.

palavras-chave método; metafísica; evidência; dúvida; idéia; existência.

...\& à l'ouverture du livre, il tomba sur le vers

Quod vitae sectabor iter?

Baillet, Vie de Monsieur Des-Cartes.

\section{Forma e conteúdo}

À primeira vista, entre as Regras para a direção do espírito (1628?) e as Meditações de filosofia primeira (1641/1647), a diferença parece ser simplesmente aquela entre um escrito de método e uma obra de metafísica. Como se as Regras procurassem estabelecer, em registro meramente formal, os preceitos de um método cuja mais eminente aplicação in concreto fosse

Recebido em 19 de dezembro de 2007. Aceito em 17 de janeiro de 2008.

doispontos, Curitiba, São Carlos, vol. 5, n. 1, p.43-66, abril, 2008 


\section{4}

desempenhada pelas Meditações. Contudo, esse esquema da diferença entre método e metafísica, amparado na maneira mais abstrata da distinção entre forma e conteúdo, precisa necessariamente ser abandonado tão logo questionemos de que forma e conteúdo se tratam, quando o assunto é o pensamento metafisico de Descartes. ${ }^{1}$

A princípio, a forma de um tal pensamento é a da ciência, "um conhecimento certo e evidente" (DESCARTES, 1999, p. 5; AT, X, 362); o seu conteúdo, "a existência de Deus e a imortalidade da alma" (DESCARTES, 1994, p. 105; AT, IX-1, 4). Como é sabido, em Descartes, a ciência de Deus e da alma, precisamente para erigir-se à condição de conhecimento certo e evidente, deve principiar com a colocação em dúvida de "todas as opiniões a que até então dera crédito" (DESCARTES, 1994, p. 117; AT, IX-1, 13). Contudo, dependendo de como se interpretam a natureza e o alcance da dúvida - por exemplo, como incidindo até mesmo sobre a equivalência entre evidência e verdade, formulada pelo Discurso do método (1637) a propósito do primeiro preceito metódico ${ }^{2}$-, a dúvida, em sua dimensão propriamente metafísica, recai sobre a validade intrínseca da razão e, daí, sobre o próprio método: à metafisica, portanto, não pode subjazer sem questionamento nenhum pressuposto, ainda que meramente formal, ou seja, atinente apenas à natureza da razão.

Nesse sentido, a metafísica deve ser por si mesma capaz de fundar a validade do método, sem poder se beneficiar antecipadamente - a não ser, como diz Husserl, "sob a forma hipotética e a título de generalidade[s] fluida[s] e indeterminada[s]" (HUSSERL, 2001, p. 26) - de preceitos formais, reguladors da estrutura e do procedimento de uma verdadeira ciência, regras por cuja aplicação eficaz ela, a metafísica, chegaria necessariamente à ve rdade dos seus conteúdos. Assim pois, a metafísica precederia o método; a rigor, a metafisica seria o próprio "método", entendido concretamente, aquém da distinção abstrata entre a forma e o conteúdo do pensamento, como "o verdadeiro caminho pelo qual uma coisa foi metodicamente descoberta [inventée]" (DESCARTES, 1994, p. 231; AT, IX-1, 121). Em suma, se a metafísica vai ao extremo de questionar a validade da razão como sujeito do pensamento metafísico, então o método não pode ser dito, do ponto de vista mais fundamental, a forma desse pensamento; ele seria, ao lado de Deus e da alma - na verdade, concernido pela existência de Deus e pela natureza da alma - 
mais um dos conteúdos da metafísica e, quiçá, um dos seus resultados, de aplicação própria no conhecimento da natureza.

Mas essas considerações bastante gerais seriam suficientes para decidir a favor de uma prioridade do discurso metafisico das Meditações frente ao projeto epistemológico das Regras? Certamente não. Com elas, pretendemos propor, a título apenas heurístico, que as Meditações é que podem fundamentar a epistemologia das Regras, mas, com isso, não está decidido que elas necessariamente o fazem, ou que o fazem apenas restritivamente. Porém, admitindo-se por hipótese a prioridade da metafisica frente ao método, que compromisso as Meditações ainda manteriam, em vista de sua própria possibilidade, com as Regras? A esse respeito, em favor de uma compreensão do itinerário cartesiano das Regras às Meditações, seria demais querer sustentar, com base na crítica da evidência supostamente operada pela dúvida metafísica, que nas Meditações Descartes submete a epistemologia das Regras a alguma espécie de revisão ou mesmo a uma crítica? Se sim, que conseqüências adviriam disso para tal epistemologia, através de cujas lentes, ao menos nos quadros do pensamento contemporâneo, a metafísica de Descartes não raro costuma ser preferencialmente visada?

Por ora, gu rdemos essas questões de teor mais abrangente, as quais não teríamos no momento como responder, e passemos a considerar, em vista das mesmas, pelo menos duas maneiras, bastante divergentes, de encaminhar o problema do qual partimos.

\section{Método versus metafísica}

2.1. Em termos bem mais moderados, a interpretação de Gueroult vai nessa mesma direção, a de confirmar a prioridade da metafísica sobre o método. Numa consideração preliminar sobre a gênese do sistema cartesiano, ele argumenta que, embora "as Meditações se desenvolvam conformemente às regras de um método que prescreve seguir o encadeamento necessário das razões", método esse "já constituído antes delas" (GUEROULT, 1968, p. 30), não se segue disso que a metafisica se constitua como não mais do que uma aplicação do método, ainda que dirigida às mais elevadas questões. 
Em verdade, afirma Gueroult, as Meditações fundam a validade do método - não apenas como instrumento cognitivo mas, ousamos acre scentar, como a forma a priori do conhecimento -, de modo que, entre elas e as Regras, se estabeleceria como que um círculo naturalmente virtuoso: as primeiras "revelam um fundamento último que, mesmo sendo obtido por meio do método, possui uma evidência intrínseca tal que, uma vez alcançado, a p a rece como válido por si, independentemente do procedimento mediante o qual se chegou a ele" (GUEROULT, 1968, p. 30). Desse modo, as Meditações "ao mesmo tempo utilizam e fundam" o método (GUEROULT, 1968, p. 30), que as Regras, "atendo-se a nenhum outro princípio além da faculdade humana do saber", tratariam de expor e justificar dentro de certos limites, os dessa mesma faculdade "em sua autêntica manifestação original, a saber, as matemáticas” (GUEROULT, 1968, p. 31).

Assim, em contrapartida ao papel fundante das Meditações, e justamente por essa sua limitação à “certeza imanente à razão humana”, as Regras - empreendendo uma investigação sobre o valor subjetivo da evidência como certeza, e não ainda, como é o caso das Meditações, sobre o seu valor objetivo como índice da verdade - manteriam "uma validade independente da metafísica" (GUEROULT, 1968, p. 31). Por conseguinte, segundo a interpretação de Gueroult, as Regras e as Meditações guardariam entre si uma relativa independência: proporcional, de um lado, à sua mútua solidariedade como textos dedicados a tarefas distintas embora intimamente associadas, e essencial, de outro, à garantia do equilíbrio interno do sistema cartesiano, ao menos na perspectiva de sua gênese.

2.2. Contudo, em outra possível avaliação do mesmo problema, o fato de que as Regras se restringem, antes de mais nada, à consideração do valor subjetivo da evidência poderia, inversamente, ser interpretado como signo privilegiado de sua eventual prerrogativa sobre as Meditações. Desse ponto de vista, o método, previamente estabelecido pelas Regras em vista da natureza universal da "sabedoria humana", 3 determinaria a metafisica em seu princípio (a saber, a confirmação da "regra geral" da verdade) bem como em seu fim (qual seja, a ciência como "conhecimento certo e evidente") e iria, portanto, muito além de apenas oferecer meios 
provisórios, porventura definitivos, para o conhecimento da verdade das coisas em si mesmas. Numa tal avaliação da co-pertinência entre método e metafisica, a epistemologia absorveria por completo a filosofia primeira.

Com efeito, encontramos à base dessa avaliação a tese de que o "princípio" supremo da metafísica consiste na própria evidência, tal como subjetivamente justificada pelas Regras e objetivamente aplicada pelas Meditações. Certamente, essa tese supõe que a evidência metódica seja, em alguma medida, invulnerável à dúvida metafisica: ela não admitiria, nem precisaria admitir, nenhum outro princípio para ser legitimada como equivalente à verdade em sentido absoluto. ${ }^{4}$ Assim, a evidência careceria de fundamento porque coincidiria com o próprio fundamento - não apenas epistemológico, mas genuinamente metafísico - do conhecimento.

Esse é o caso da interp retação de Heidegger, para quem a metafísica de Descartes “oculta o predomínio do método, cunhado a partir das Regras" (HEIDEGGER, 1992, p. 112). Por método, Heidegger compreende o "projeto matemático" de fundação do que as Regras chamam mathesis universalis: nas palavras de Descartes, "uma ciência geral que explica tudo quanto se pode procurar com referência à ordem e à medida" (DESCARTES, 1999, p. 22-23; AT, X, 374), ou ainda, "uma disciplina [que] deve conter os primeiros rudimentos da razão humana e estender sua ação até extrair as verdades de qualquer assunto que seja" (DESCARTES, 1999, p. 27; AT, X, 378). Segundo Heidegger, esse projeto epistemológico traduziria uma decisão "acerca da essência e da possibilidade [...] do ente em geral": o que uma coisa é e que ela seja só se decide "a partir de conceitos que se obtêm através do puro pensar": "o particular enquanto tal deve deduzir-se a partir de princípios, do universal considerado como axiomático" (HEIDEGGER, 1992, p. 112-113). Nesse sentido, o ente em geral é projetado por e a partir do pensamento, tomado em sua estrutura lógico-proposicional. Essa estrutura, Heidegger a denomina o "matemático", na medida em que com base nela é determinado antecipadamente, em conformidade com princípios e conceitos do pensamento puro, o que e se o ente em geral pode ser. Contudo, o que principalmente define o projeto matemático é que "não haveria uma doação das coisas anterior" (HEIDEGGER, 1992, p. 106) àquilo que o pensamento pode formalmente, segundo suas regras próprias, conceber com evidência e certeza. 
Para Heidegger, as Regras de Descartes estabelecem a estrutura do matemático e, portanto, como implicariam uma decisão sobre a essência do ente em geral, constituem ao mesmo tempo uma metafisica, a metaphysica generalis ou ontologia. Sem se limitar à forma do pensamento metafísico, o método sobre-determina o seu conteúdo, tornando-se, assim, a própria metafisica: "a metafisica é agora matemática” (HEIDEGGER, 1992, p. 113). Nesse sentido, as Meditações estariam para as Regras como a metaphysica specialis para metaphysica generalis. colocando em questão Deus, a alma e o mundo, elas tratariam de "domínios particulares do ente" previamente projetado em seu ser segundo o "traço matemático fundamental" aduzido pelas Regras (cf. HEIDEGGER, 1992, p. 112113). Ao proceder metodicamente, o pensamento outorgaria às coisas, unicamente a partir de si, sua verdade metafisica.

2.3. Seguindo Heidegger, Marion levará essa interpretação às últimas conseqüências, desenvolvendo uma leitura das Regras ao longo da qual mostra que a epistemologia cartesiana se constitui num confronto minucioso com a ontologia de Aristóteles. Decisiva na leitura de Marion é a demonstração de como Descartes executa uma inversão da tábua aristotélica das categorias, substituindo a categoria de substância pela de relação, que viria ocupar o primeiro lugar na hierarquia dos modos de ser (cf. MARION, 1997, p. 107-128). Mais do que isso, Marion pretende que, nas Regras, as determinações do ser se convertem em maneiras de pensar, como graus de evidência que o pensamento pode conquistar por si. Nisto consiste o privilégio da relação: a sua eficácia não se deveria simplesmente à possibilidade de as coisas poderem ser "conhecidas umas pelas outras" (DESCARTES, 1999, p. 31; AT, X, 381), mas residiria sobretudo em que elas só podem se determinar umas em relação às outras porque antecipadamente "estão sujeitas [subjecta] ao exame de nossa inteligência" (DESCARTES, 1999, p. 54;AT, X, 398), à qual, portanto, seriam essencialmente relativas, sub-ordenadas. Marion discute em pormenor todas as ocasiões em que as Regras descartam ou, confome prefere dizer, "alienam" (MARION, 1997, p. 265) as coisas em sua subsistência separada, ${ }^{5}$ como se a sua "desrealização em objetos" fosse condição primeira de possibilidade da ciência, projetada por Descartes, como um saber unive rsalmente certo e evidente (cf. MARION, 1997, p. 265). 
A leitura de Marion acirra a interpretação proposta por Heidegger, por meio da sugestão de que, ao fim e ao cabo, a metafisica cartesiana se esgota inteiramente no método. Não que o método seja essa metafísica, mas sim que a metafísica se dissolve, por antecipação, numa epistemologia. Obviamente, essa epistemologia sustenta, em seu princípio, uma "relação ontológica”, na qual "o ego reconstrói um objeto conforme às condições de exercício do saber, objeto cujo princípio passa da ousía para o ego" (MARION, 1997, p. 262). Contudo, trata-se a rigor da redução, através de uma ontologia instrumental, de toda possível realidade a um saber, somente ele "real"; e não "simplesmente" da reconfiguração da estrutura metafísica da realidade em função de um possível saber sobre a mesma, conforme Heidegger parece manter. ${ }^{6}$

Nesse sentido, a metafisica é banida pelo método. Não há verdade metafísica; só há ve rdade epistemológica. A evidência do pensamento exclui a natureza das coisas. ${ }^{7}$ De maneira conseqüente, Marion atribui às Meditações o papel dessa ontologia instrumental, o de fornecer o fundamento "metafísico" requerido pelo projeto epistemológico das Regras: "As Regulae não mantêm com as Meditações nenhuma relação de anunciação, nem de antecipação, mas, como pensamento do objeto, tendem para isso, como para o pensamento do fundamento do objeto" (MARION, 1997, p. 256). Esse fundamento “metafísico", que as Meditações estariam destinadas a descortinar, mas apenas em vista das Regras, equivale precisamente ao ego pensante, como sujeito do saber das coisas "desrealizadas" em objetos: a "subjetividade moderna” (MARION, 1997, p. 262). Dessa maneira, o pensamento das Regras reclamaria as Meditações somente para, em seguida, depô-las - à semelhança da famosa escada que se joga fora, depois de provisoriamente ter cumprido sua função.

\section{Dúvida metafísica e evidência intelectual}

Retomemos o problema. Partimos acima, com Gueroult, da consideração conciliatória de que, embora utilize o método, a metafisica o funda; chegamos agora, através de Heidegger e com Marion, a uma consideração adversária: o método utiliza a metafísica para se fundar a si mesmo. Assim sendo, perguntamos: como solucionar esse impasse, que parece impor-se 
necessariamente uma vez que se tome como medida exclusiva de avaliação do problema ora a metafísica das Meditações, ora o método das Regras? Ao que nos parece, a solução envolve a questão acerca do estatuto da evidência, decisiva para a compreensão do que é a metafísica desenvolvida nas Meditações, precisamente porque problematiza, de forma direta, temas fundamentais da epistemologia elaborada nas Regras. Acerca dessa questão, limitaremo-nos aqui a duas considerações, feitas menos com o intuito de respondê-la do que com o de indicar um encaminhamento possível para tanto.

3.1. Questionar o estatuto da evidência é perguntar pelo valor de verdade das "essências matemáticas", no sentido amplo das "coisas muito simples e muito gerais", ${ }^{8}$ que são colocadas em dúvida, na Primeira Meditação, com o argumento do Deus Enganador. A verdade dessas "coisas" independe de sua existência in rerum natura: ela se mede exclusivamente pela certeza e indubitabilidade com que aparecem ao pensamento, ou seja, por sua evidência. ${ }^{9}$ Nesse sentido, é legítimo considerar que essas "coisas muito simples e muito gerais" correspondem às "naturezas puras e simples" a respeito das quais as Regras afirmam que o entendimento não pode, sempre que as intui, jamais estar enganado. ${ }^{10}$ Por naturezas simples, Descartes entende tanto conteúdos elementares de coisas possíveis - as "naturezas puramente intelectuais" e as "naturezas puramente materiais" - quanto formas elementares do pensamento sobre essas coisas - as "noções comuns" (DESCARTES, 1999, p. 83-84; AT, X, 419-420).11 Segundo as Regras, a intuição das naturezas simples, tomadas em ambos os sentidos, se define mesmo por não admitir nenhuma dúvida sobre sua verdade (cf. DESCARTES, 1999, p. 13-14; AT, X, 368).

Ora, a Terceira Meditação reformulará o argumento do Deus Enganador para fazer recair justamente sobre as naturezas simples, indubitáveis (em ambos os sentidos, tanto como conteúdos quanto como formas elementares do pensar) do ponto de vista estritamente metódico, a dúvida metafísica: "se acaso quisesse, lhe seria fácil [ao Deus Enganador] fazer com que eu errasse também nas coisas que creio ver por intuição como as mais evidentes aos olhos da mente [mentis oculis quam evidentissime intueri]" (DESCARTES, 1992, p. 96; AT,VII, 36). Daí que, "sem o conhecimento dessas duas verdades", a saber, "se há um Deus" e "se ele pode ser 
enganador", 12 não seja possível "jamais estar certo de coisa alguma" (DESCARTES, 1994, p. 138-139; AT, IX-1, 28-29). Assim temos que, nas Meditações, para espanto das Regras, uma "opinião preconcebida" (DESCARTES, 1994, p. 138; AT, IX-1, 28) - obscura e confusa, portanto carente de toda evidência - acerca da origem da razão torna-se uma "razão de duvidar" da evidência como tal. ${ }^{13}$ Mas, na medida em que a evidência constitui, como as Regras parecem supor, a forma a priori da razão, esse "juízo inverificável”, pelo qual se supõe a existência de um Deus Enganador, engendra o seguinte paroxismo: uma razão de duvidar da "validade da [própria] razão" (VILLORO, 1965, p. 66).

Com isso, a racionalidade se amplia a limites que excedem absolutamente aqueles do pensamento metódico das Regras, ${ }^{14}$ porque ultrapassam os do entendimento finito, para coincidir com a wontade, "tão vaga e tão extensa que não está encerrada em quaisquer limites" (DESCARTES, 1994, p. 163; AT, IX-1, 45). Convém notar que, na única menção que fazem à vontade, as Regras lhe atribuem a função do poder de acreditar no que é da ordem da "revelação divina": "a fé que lhe testemunhamos, relativa em todos os casos a coisas obscuras, não é um ato do espírito, mas da vontade [non ingenii actio sit, sed woluntatis]" (DESCARTES, 1999, 16; AT, X, 370). Quer dizer, as Regras só admitem a intervenção da vontade a propósito da fé, silenciando sobre a sua função e importância no conhecimento.

Nas Meditações, diferentemente, a vontade desempenha um papel fundamental: já na Primeira Meditação, é ela que, implicitamente, concede à dúvida o seu alcance metafísico, elevando-se sobre o entendimento finito para remetê-lo à sua origem em um poder superior, o do Deus Enganador. É ela também que, através de um "esforço contra a natureza" (GUEROULT, 1968, p. 38), acirra a dubitabilidade do entendimento ao “instituir a ficção do Gênio Maligno" (GUEROULT, 1968, p. 39): um mito que sistematicamente põe em crise a esfera inteira do saber evidente. Nesse sentido, a vontade perfaz a condição, por assim dizer, moral do empreendimento cartesiano (cf. TEIXEIRA, 1990, p. 23-41): por mais que se ampare em "razões de duvidar", razões essencialmente provisórias, o ato da dúvida só é possível, antes de mais nada, por uma resolução: "desde que tomei a resolução de pôr em dúvida todas as coisas [ex quo de omnibus volui dubitare]" (DESCARTES, 1992, p. 138; AT, VII, 
56). Sobretudo, a vontade é explicitamente referida, na Quarta Meditação, ao lado do entendimento, como condição sine qua non do ato de conhecimento: ela consiste no poder de julgar, a saber, de afirmar ou negar o ser e o não-ser das coisas cuja possibilidade reside nas idéias concebidas no entendimento. Conceber algo não é ainda conhecê-lo: para tanto, requerse um juízo e, assim, o concurso da vontade, capaz de "erguer pretensão de verdade" ao afirmar o conteúdo de uma idéia e, assim, referi-lo como representação a algo realmente existente (cf. LANDIM, 1992, p. 33). No ato de julgar, a vontade é infinita; e, segundo Descartes, é por sua infinitude que reconhecemos em nós "a imagem e a semelhança de Deus", pois, considerada "formal e precisamente nela mesma", a vontade parece não ser maior em Deus do que em nós mesmos (DESCARTES, 1994, p. 163-164; AT, IX-1, 45-46).

Esse contraste entre as Regras e as Meditações quanto ao papel da vontade nos convida à formulação da seguinte hipótese: a de que o proj eto científico das Regras, elaborado, como quer Marion, no sentido da substituição da metafísica por uma epistemologia, tem por condição que a vontade seja abstraída da operação de conhecimento, muito embora uma tal substituição, fundada na equivalência (simplesmente postulada nas Regras) entre evidência e verdade, não deixe nunca de ser resultado de uma "decisão": nesse caso, a vontade se limitaria a si mesma, colocandose "fora de jogo" a fim de que o entendimento como que pudesse ter forjada a sua "infinitude" em vista do estabelecimento de um saber universalmente certo e evidente. Não obstante o eventual exagero dessa hipótese, o referido contraste permite ver como a "atitude moral" (TEIXEIRA, 1990, p. 27) do empreendimento cartesiano vem explicitamente à tona nas Meditações, onde a vontade - na forma da resolução por duvidar de tudo, por submeter-se a Deus ${ }^{15}$ e, com isso, por conter o conhecimento intelectual dentro dos limites impostos pela natureza divina - assume o primeiro plano.

Contudo, mais importante é notar que tal valorização da vontade traz consigo a tese da finitude do entendimento, faculdade que, mediante a operação voluntária da dúvida, é afirmada como sendo “de extensão muito pequena e grandemente limitada" (DESCARTES, 1994, p. 163; AT, IX-1, 45). Reconhece-se, desde então, que a evidência clara e distinta não constitui por si só um conhecimento; logo, que uma concepção 
por si evidente não pode sozinha atribuir-se o que poderá fazer dela uma verdade, e isso apenas por obra da vontade, faculdade metafisica. Pretensão que, pelo contrário, as Regras parecem sustentar, com a proposição do ideal de um saber cujas condições se resumiriam todas ao método, isto é, ao uso auto-re fe rente do entendimento, não admitindo nenhuma limitação de outra parte (cf. DESCARTES, 1999, p. 2; AT, X, 360).

Constatamos assim que as Meditações exibem o trabalho de uma racionalidade que não se orienta exclusivamente pelo critério metódico da evidência ou, como diz Gueroult, pela razão "em sua autêntica manifestação original", o saber matemático. Tratar-se-ia de uma racionalidade que, sendo metafísica, se torna por isso, em alguma medida, a-matemática? Seja como for, em vista do que dissemos acima, será preciso concordar com Beyssade na afirmação de que, à diferença da epistemologia das Regras, "a metafísica [cartesiana] não fecha de modo nenhum a razão sobre ela mesma. [...] A metafísica é o lugar de uma auto-crítica da razão. Ela descobre uma ordem sem medida e para além de toda medida, à qual se mede a ordem do mensurável e, portanto, a razão em seu uso ordinário" (BEYSSADE, 2001, p. 320).

3.2. As Meditações não apenas decidem suspender a equivalência entre verdade e evidência, como também descobrem, por assim dizer, outro conceito de verdade aplicado do conhecimento, sobre o qual elas farão repousar a validade desde então limitada ${ }^{16}$ do primeiro: o conceito de verdade como correspondência entre pensamento e coisa. Como é sabido, na Terceira Meditação, tal conceito preside a prova a posteriori da existência de Deus, em que a realidade formal de um ente é demonstrada a partir de sua realidade objetiva. Com efeito, não seria demais assumir essa prova como etapa principal de resolução daquele que Gueroult julga ser o "problema fundamental" da metafísica cartesiana: "Podemos julgar validamente que a uma idéia, mesmo suposta verdadeira, corresponde alguma coisa de real? Ou seja, a realidade exterior a mim responde às exigências internas do entendimento? Com que direito podemos concluir das essências verdadeiras às existências fora dessas essências?" (GUEROULT, 1968, p. 31). Problema esse, o do "valor objetivo de nossos conhecimentos", "que as Regras ignoram" (GUEROULT, 1968, p. 34, nota 3), mas que, segundo Marion, elas ignoram ativamente, em virtude de uma 


\section{4}

"decisão" de ordem ontológica pela qual a coisa, em sua subsistência separada, é substituída por "um objeto, ente que é inteiramente submetido às exigências do saber" (MARION, 1997, p. 259).

Quando, nas Regras, Descartes fala em "ve rdade das coisas" (DESCARTES, 1999, p. 13; AT, X, 367), é preciso ter em conta que essas "coisas", ditas verdadeiras, são "naturezas puras e simples que podemos ver por intuição" (DESCARTES, 1999, p. 34; AT, X, 383), ou seja, "conceito[s] que a inteligência pura e atenta forma com tanta facilidade e clareza que não fica absolutamente nenhuma dúvida sobre o que compreendemos" (DESCARTES, 1999, p. 14; AT, X, 368). Aí, o valor de verdade dos conteúdos de pensamento é medido exclusivamente por sua evidência, abstração feita de sua validade objetiva como representações das coisas em sua "natureza isolada" (DESCARTES, 1999, p. 32; AT, X, 381), como se "falássemos delas enquanto realmente existentes" (DESCARTES, 1999, p. 82; AT, X, 418). Assim, "do lado da realidade" (a pa tre rei), as coisas não passariam de suposições inverificáveis, ao passo que, "com respeito ao nosso entendimento" (respectu intellectus nostri), consistiriam em naturezas compostas, redutíveis a elementos simples absolutamente evidentes (DESCARTES, 1999, p. 82; AT, X, 418). O próprio "lado da realidade" não constituiria senão uma perspectiva obscura do entendimento sobre as coisas, essencialmente redutível, por meio do método, à perspectiva “absoluta" do conhecimento certo e evidente.

Dessa maneira, as Regras elaboram um conceito de verdade que exclui de sua definição a conformidade com as coisas: os pensamentos, na condição (de intuições) de naturezas simples, são, ou sempre podem ser, verdadeiros em si mesmos. Para Marion, porém, esse conceito de verdade estende sua soberania para além das Regras, presidindo a metafísica das Meditações, na qual ele jamais poderia ser posto em questão sob risco de se aniquilar o itinerário metafísico que, desde o Cogito, contaria forçosamente com a equivalência, tida como absolutamente indubitável, entre evidência e verdade (cf. MARION, 1996, p. 49-83).

Contudo, quanto a esse ponto, as Meditações parecem claramente divergir das Regras: não bastasse a dúvida metafisica da Primeira Meditação, na "teoria das idéias" elaborada ao longo da Terceira Meditação, Descartes se compromete com a tese de que "consideradas em si mesmas, isto é, somente como modos representativos do pensamento sem relação a 
coisas exteriores, as idéias não são nem verdadeiras nem falsas" (LANDIM, 1992, p. 32). Nesse contexto, a ve rdade das idéias é medida pela possibilidade de sua correspondência às coisas em si mesmas, correspondência que, uma vez estabelecida no nível ontológico, se justifica como princípio que se estenderá legitimamente a todo conhecimento. ${ }^{17}$ Com efeito, a "outra via” (DESCARTES, 1994, p. 143; AT, IX-1, 31) de exame da verdade das idéias que Descartes inaugura na Terceira Meditação se caracteriza justamente pela consideração das mesmas em sua realidade objetiva, na qual se afirma a imperfeição e a dependência dos objetos nas idéias em relação a possíveis realidades formais, tidas como suas causas. ${ }^{18}$

Essa consideração metafísica sobre o ser das idéias subentende a própria redefinição do conceito de idéia: não é mais suficiente defini-las, como as Regras pareciam fazer a propósito do conceito de "natureza simples", como "obra[s] do espírito" (DESCARTES, 1994, p. 144; AT, IX-1, 32), "conceito que nasce apenas da luz da razão" (DESCARTES, 1999, p. 14;AT, X, 368); é preciso igualmente, a fim de explicar a presença dos objetos no espírito, reportá-las a uma existência, formal ou eminente, que atua como causa de sua pensabilidade. É nesse sentido que lemos no Axioma X da "Exposição Geométrica" das Segundas Respostas: "na idéia ou no conceito de cada coisa, a existência está contida, porque nada podemos conceber sem que seja sob a forma de uma coisa existente" (DESCARTES, 1994, p. 238; AT, IX-1, 128). Seja meramente lógica ou formalmente real, essa existência é, como toda existência, uma da qual somos autorizar a perguntar pela causa, ${ }^{19}$ de maneira que, seja como for, a possibilidade real de uma coisa é, no limite, apontada como condição sem a qual não poderíamos pensá-la a título de objeto. Ora, essa redefinição do conceito de idéia traz supostamente consigo um redimensionamento da própria evidência intelectual. Evidente não será mais aquilo que simplesmente transparece ao espírito humano, podendo ser explicado por referência a esse mesmo espírito apenas, mas o que, assim transparecendo, reenvia a uma existência formal ao menos possível.

Levado a seu termo mediante a prova a posteriori da existência de Deus, esse desenvolvimento conduz à tese da veracidade divina como condição (transcendente) da possibilidade de um pensamento verdadeiro, ou seja, de um conhecimento: "toda concepção clara e distinta é sem dúvida algo de real e de positivo, e portanto não pode ter sua origem no 
nada, mas deve ter necessariamente Deus como seu autor" (DESCARTES, 1994, p. 169; AT, IX-1, 49-50). Isso nos mostra que a veracidade divina não vem somente "garantir" a evidência clara e distinta como critério de verdade; antes, ela vem explicar a possibilidade de uma evidência. Do ponto de vista metafísico, o evidente ao espírito humano é de certo modo revelado ao espírito humano por Deus como "autor" de toda concepção clara e distinta: "sua presença funda todas as idéias", pois "não se pode pensar uma coisa finita senão a partir do infinito" (ALQUIÉ, 2000, p. 213, cf. também 250).20 O que nos permite reconhecer que, nas Meditações, a equivalência entre evidência e verdade, fundante da epistemologia das Regras, é resultado, antes que condição, do itinerário metafísico.

A essa interpretação poder-se-ia naturalmente objetar que, baseandose numa evidência de ordem intelectual, a prova a posteriori da existência de Deus demanda o emprego do critério, ou melhor, da "regra geral" de verdade. Mas é preciso notar que, embora Descartes diga que a idéia de Deus é "a mais clara e distinta de todas as que se acham em meu espírito", ele afirma também no mesmo contexto que, não obstante, Deus é incompreensível por sua idéia (DESCARTES, 1994, p. 151; AT, IX-1, 37). ${ }^{21}$ Com efeito, se ser "objetivamente por re presentação no entendimento por uma idéia" é uma "maneira imperfeita de ser" (DESCARTES, 1994, 145; AT, IX-1, 33), a condição de objeto de uma idéia absolutamente não convém a Deus enquanto ente sumamente perfeito. De modo que o conhecimento de que Deus, fundamento da evidência e da verdade das idéias, existe supostamente não padeceria da insuficiência de que padecem todos os pretensos conhecimentos na ignorância de sua existência.

Porém, isso não vem pôr em questão a possibilidade mesma de uma idéia de Deus? Afinal, de que maneira se conciliam, na idéia de Deus, considerada como ato de um pensamento finito, máxima evidência e absoluta incompreensibilidade? Além disso, se é certo, ao menos segundo a epistemologia das Regras, que ser evidente ao pensamento é ser compreensível por um pensamento (cf. DESCARTES, 1999, p. 14;AT, X, 368), a idéia de Deus não constituiria uma exceção "de fato" a essa noção de evidência, impondo com isso uma redefinição ainda mais radical, mesmo no que se refere ao contexto metafísico das Meditações, do conceito de idéia? 
Mais ainda, se a idéia de Deus é a idéia do ser ou da existência, ${ }^{22}$ não se torna igualmente questionável a possibilidade de uma intuição de Deus e, portanto, do ser, ou seja, que o entendimento seja efetivamente capaz do conhecimento do existente? Ou seja: o existente pode enquanto tal tornar-se objeto de uma intelecção, se é ve rdade que, como as Regras já pareciam propor distinguindo as coisas na medida de nosso entendimento das coisas em sua natureza isolada (cf. DESCARTES, 1999, p. 31-32, 82; AT, X, 381, 418), "ser objeto é ter sua essência separada da existência" (ALQUIÉ, 2000, p. 231)? Ou será que a referência cognitiva ao existente - e, em particular, a Deus, o único necessariamente existente - se faz por outra via, não simplesmente intelectual? Mas, nesse caso, qual seria?23

Sem pretender resposta a essas perguntas, contentamo-nos aqui em indicar a sua re levância para a compreensão da metafísica de Descartes, destacando especialmente que a noção mesma de evidência, inquestionada nas Regras, sendo nelas a abstração da natureza isolada das coisas condição sine qua non para a intuição do objeto simples do conhecimento, se torna, nas Meditações, consideravelmente mais complexa, senão mesmo aporética, uma vez que, aí, a evidência intelectual só se deixa explicar, quanto à sua possibilidade e verdade, por meio da referência problemática ao existente como causa, e isso de duas maneiras: como causa, no sentido correspondencial, da realidade objetiva das idéias e como causa, no sentido eficiente, da própria forma clara e distinta das idéias (Deus como “autor” de toda evidência do entendimento).

\section{Entre saber e ser}

Se essas breves indicações são pertinentes, podemos confirmar, na passagem das Regras às Meditações, a prioridade da metafísica sobre o método; mas, ao mesmo tempo, precisaríamos reformular a tese segundo a qual o método das Regras dispõe de uma "validade independente" da metafísica das Meditações. Pois, bem ao contrário de testemunhar uma solidariedade imediata entre método e metafísica no interior do mesmo projeto de fundamentação, essa independência significaria um conflito aparentemente insuprimível entre duas "metafisicas" rivais: a ontologia instrumental das Regras e teologia fundamental das Meditações. 
Daí advém, como conseqüência particularmente importante, a descontinuidade entre metafisica e ciência no sistema cartesiano: por mais que a metafísica ofereça à ciência seu fundamento, a certeza e a evidência metafisicas são, ao que parece, de natureza completamente diversa das da ciência. Como se pode antever, essa consideração, levada ao limite, poria em xeque a sistematicidade da filosofia de Descartes; e isso por força do elemento propriamente metafísico que intervém na meditação cartesiana: a idéia de Deus. Desse ponto de vista, seria uma tarefa importante determinar até que ponto o conhecimento metafísico, em especial o da existência de Deus, incompreensível e por isso imensurável, admite sua inserção numa "ordem de razões" - ao menos no sentido das Regras, onde o que cai sob a ordem do pensamento é por isso mesmo mensurável pelo pensamento (cf. DESCARTES, 1999, p. 27; AT, X, 377-378) - sem no entanto provocar a ruptura da própria ordem racional. ${ }^{24}$

Em vista disso, Alquié sustenta uma diferença essencial entre "idéias científicas" e "idéias metafísicas": as primeiras sendo "contidas no pensamento, limitadas, podendo ser cernidas e compreendidas pelo espírito e, portanto, colocadas em dúvida e negadas"; e as segundas, "que preferimos denominar presenças", não podendo ser negadas pelo espírito, "pois ele não as contém" (ALQUIÉ, 2000, p. 229). A tese principal de Alquié é a de que "o pensamento só nega os seus objetos, e o ser não é o seu objeto” (ALQUIÉ, 2000, p. 229): ou seja, a tese de que não há, em Descartes, intelecção objetiva do ser, sendo os objetos marcados por uma "insuficiência ontológica” irredutível (ALQUIÉ, 2000, p. 232). Daí se conclui que "a ciência é duplamente limitada, pelo Ser que funda suas verdades e pelo ser que toma consciência delas; portanto, nem Deus nem o homem podem, pela ciência, ser conhecidos a título de objetos" (ALQUIÉ, 2000, p. 208-212); e, em termos mais gerais, que, "se a ciência é o domínio do Ser perdido, a metafísica é o domínio do Ser reencontrado" (ALQUIÉ, 2000, p. 219).

A essa interpretação opõe-se frontalmente a de Gueroult, para quem "a metafísica não é nada de outro que uma ciência, como a matemática e a física", não diferindo delas senão "por seus objetos, que são tomados totalmente do entendimento puro por exclusão do concurso de toda outra faculdade" (GUEROULT, 1968, p. 62). Dessa maneira, Gueroult assume que a certeza e a evidência metafísicas não são de ordem diversa, 
mas "a certeza e a evidência [as mesmas que as da ciência] estabelecidas como tais" (GUEROULT, 1968, p. 63); o que é essencial para garantir-se o caráter sistemático da filosofia de Descartes. A exemplo disso, no que se refere ao conhecimento da existência de Deus, Gueroult afirma que "Deus é posto como causa de minha idéia a partir de minha idéia; é, portanto, a luz do meu entendimento que se esclarece a si mesma", de modo que a inspiração da metafísica cartesiana "não cessa de ser idealista e não se confunde, nesse caso particular, com um resquício da ontologia antiga" (GUEROULT, 1968, p. 246).

Ao nosso ver, o desacordo entre essas interpretações, proveniente de uma dificuldade real da filosofia de Descartes, só pode ser resolvido, conforme procuramos mais acima indicar, mediante a elucidação da noção de evidência e a conseqüente mensuração do papel do entendimento na constituição da metafísica cartesiana, particularmente na medida em que o entendimento é afetado pela dúvida e em que, não obstante, ele entra em jogo na prova a posteriori da existência de Deus. Por mais que a interpretação de Alquié nos pareça bastante pertinente ao colocar como problema a possibilidade de uma concepção intelectual da existência, não podemos deixar de reconhecer certa artificialidade na proposição da diferença entre uma espécie "metafísica" e outra "científica" de idéias; afinal, Descartes aparentemente sempre emprega o termo de modo unívoco. Por outro lado, a interpretação de Gueroult, na qual se afirma, mais do que a continuidade, uma autêntica homogeneidade entre metafísica e ciência, parece diminuir o alcance da dúvida hiperbólica e, conseqüentemente, hipostasiar a capacidade do entendimento no conhecimento metafísico. Afinal, a tese de Descartes, tal como ele a exprime literalmente, não é de modo nenhum a de que "Deus é posto [...] a partir de minha idéia": é justamente a contrária. A orientação idealista dessa interpretação, alheia à metafísica de Descartes, fica patente ao compararmo-la com a seguinte passagem da TerceiraMeditação: "E cert amente não se deve achar estranho que Deus, ao me criar, haja posto em mim esta idéia [a de Deus] para ser como que a marca do operário impressa em sua obra" (DESCARTES, 1994, p. 157; AT, IX-1, 41).

Em todo caso, podemos concluir da maneira mais geral reconhecendo que tal conflito entre método e metafísica, ${ }^{25}$ dificilmente negável, nada mais faz que expor, na intertextualidade das Regras e das Meditações, 
o diálogo tenso, constitutivo do espírito mesmo da filosofia de Descartes, entre a ordem do saber e a ordem do ser: entre ego e Deus.

Entre saber e ser, quod vitae sectabor iter?

1 “Aquele primeiro momento ['a representação cristã do ente'] determina o conteúdo da metafisica moderna; o segundo ['o traço matemático fundamental'], a forma dessa metafísica. Mas esta caracterização através de conteúdo e forma é demasiado apressada para ser verdadeira" (HEIDEGGER, 1992, p. 112).

2 "O primeiro [preceito] era o de jamais acolher alguma coisa como ve rdadeira que eu não conhecesse evidentemente como tal [...] e de nada incluir em meus juízos que não se apresentasse tão clara e tão distintamente a meu espírito, que não tivesse nenhuma ocasião de pôlo em dúvida" (DESCARTES, 1994, p. 53; AT,VI, 18).

3 "Pois, como todas as ciências nada mais são senão a sabedoria humana, que sempre permanece uma e a mesma, seja qual for a diferença dos assuntos [subjectis] aos quais é aplicada, e que não recebe deles mais distinções do que a luz do sol recebe da variedade das coisas que ilumina, não é necessário impor aos espíritos [ingenia] nenhum limite" (DESCARTES, 1999, p. 2; AT, X, 360).

${ }^{4}$ Ao utilizar esse termo, temos em vista aqui o caráter absoluto que Descartes, em maior ou menor grau, reserva às "naturezas puras e simples": "[...] tudo o que se olha [ut omne id quod consideratu $]$ como independente, causa, simples, un iversal, uno, igual, semelhante, reto [...]"; “[...] o que há de mais simples e de mais fácil [...]" (DESCARTES, 1999, p. 32; AT, X, 381). Logo, no contexto das Regras, é absoluto aquilo que se conhece por si mesmo, cuja verdade, pelo fato de repousar apenas na evidência intelectual, sendo essencialmente "relativa" ao entendimento, não se mede contudo pela referência ou conformidade a nada de outro: como lemos na Primeira Meditação, "pouco cuidando se está ou não na natureza das coisas [in rerum natura]” (DESCARTES, 1992, p. 62; AT,VII, 20).

5 Por exemplo:"“...] do ponto de vista que pode torná-las [as coisas] úteis ao nosso desígnio, em que não consideramos sua natureza isolada [naturas solitarias], mas em que as comparamos entre si a fim de conhecê-las umas pelas outras [...]" (DESCARTES, 1999, p. 32; AT, X, 381); "[...] deve-se chegar às coisas mesmas [res ipsas] e só as considerar na medida em que o entendimento as atinge" (DESCARTES, 1999, p. 55; AT, X, 399); "Dizemos, pois, em primeiro lugar, que é preciso considerar cada uma das coisas em particular, em relação ao nosso entendimento [in ordine ad cognitionem nostram], de modo diferente do que se falássemos delas como realmente existentes [revera existunt]" (DESCARTES, 1999, p. 82; AT, X, 418).

${ }^{6}$ Consideramos importante determinar em que ponto Marion, ciente ou não disso, se distancia de Heidegger. Pa rece-nos que essa distância se mostra através do modo como cada qual compreende o lugar do ego pensante na estrutura do projeto matemático/epistemológico das Regras. Enquanto Marion atri bui ao ego a condição de fundamento dessa epistemologia, como "sujeito (hypokeímenon) sobre o qual se assenta o objeto do saber" (MARION, 1997, p. 262), Heidegger, diferentemente, diz que o ego só pode se tornar o "elemento caracterizador" da 
objetividade graças à “supremacia essencial [...] do matemático” (HEIDEGGER, 1992, p. 107). Assim, se, para o primeiro, é o ego, como subjectum do saber matemático, que institui a objetividade, para o segundo, pelo contrário, é o matemático, como "determinação do Ser do ente" (HEIDEGGER, 1992, p. 110), que torna possível ao ego ascender à condição de subjectum. O ego, en fatiza Heidegger, é "posto", juntamente com os objetos do saber, pela "proposição matemática” (HEIDEGGER, 1992, p. 109). A diferença é essencial. Pois, do lado de Marion, ela acarreta um compromisso com a idéia de que "a especificidade do pensamento moderno" reside em "ter confiado à 'subjetividade' [...] o papel e o estatuto de um subjectum", enquanto fundamento da época moderna, a época da subjetividade (MARION, 1997, p. 262). Do lado de Heidegger, essa diferença se traduz na idéia de que o predomínio do matemático "não tem a ver com nenhum ponto de vista do eu, com nenhuma dúvida subjetiva", enfim, com "nenhum subjetivismo" (HEIDEGGER, 1992, p. 107, 103). Para Heidegger, o"subjectum" da época moderna é, única e exclusivamente, o "Ser dos entes", pois a história da metafisica é a "história em que o movimento do Ser se torna visível" (HEIDEGGER, 1992, p.102). Cf. também MARION, 1997, p. 264-265.

7 “Natureza deve assim compreender-se não mais a partir da physis, mas da evidência, que ela qualifica muitas vezes [...]"; “[...] a natureza define-se pela possibilidade de um pensamento fácil [...]"; "Quanto à Natureza, só é possível invocá-la desde que a destituamos do que se furta à evidência e, portanto, de toda 'potência imaginária"' (MARION, 1997, p. 127).

8 “[...] coisas ainda mais simples e universais, que são verdadeiras e existentes [...]" (DESCARTES, 1994, p. 120; AT, IX-1, 15-16). Vale ressaltar que o adjetivo "existentes" é um acréscimo feito pela tradução francesa.

9 “[...] contêm alguma coisa de certo e indubitável”; “[...] e não parece possível que verdades tão patentes [si aparentes, perspicuae veritates] possam ser suspeitas de alguma falsidade ou incerteza" (DESCARTES, 1994, p. 120-121;AT, IX-1, 16; AT,VII, 20).

10 “[...] essas naturezas simples são todas elas conhecidas por si sós e não contêm nada de falso" (DESCARTES, 1999, p. 85; AT, X, 420.) Cf. também DESCA RTES, 1999, p. 14, 88; AT, $\mathrm{X}, 368,423$.

${ }^{11}$ Essa classificação é retomada nos Princípios da filosofia (1644), SS 48-50, onde as "noções comuns" são caracterizadas como "verdade[s] eterna[s] que não te[ê] $] \mathrm{m}$ qualquer existência fora de nosso pensamento" (DESCARTES, 2002, p. 63, \$ 48). Na questão acerca do estatuto da evidência, é preciso determinar se a dúvida metafísica se estende também às noções comuns enquanto formas elementares da própria atividade de pensar. Exemplos de noções comuns são o princípio de não-contradição ("é impossível que o mesmo seja e não seja ao mesmo tempo"), o princípio de razão suficiente (em sua formulação negativa: "do nada nada vem a ser") e, talvez mesmo, a "regra geral" por meio da qual é postulada a equivalência entre evidência e verdade ("todas as coisas que concebemos mui claramente e mui distintamente são todas verdadeiras"). Pressupomos, sem contudo poder comprová-lo nos limites deste texto, que a dúvida metafisica se estende, inclusive, a tais noções comuns ou "verdades eternas", de maneira que, precisamente por isso, pode ser dita metafisica. Para tanto, um texto em que se pode apoiar essa interp retação sobre o alcance da dúvida é o $\mathbb{1 3}$ dos Princípios da filosofia, onde as noções comuns são referidas, ao lado das essências matemáticas, como passíveis de dúvida na medida em que se deixa de atentar para elas, pois, como afirma Descartes

doispontos, Curitiba, São Carlos, vol. 5, n. 1, p.43-66, abril, 2008 
na Quinta Meditação, “a natureza de meu espírito é tal que não me poderia impedir de julgálas [as coisas] ve rdadeiras enquanto as concebo clara e distintamente” (DESCARTES, 1994, p. 172; AT, IX-1, 52). Ora, é justamente a natureza desse espírito, mais precisamente, a do entendimento humano, que é radicalmente colocada em dúvida através da hipótese do Deus Enganador. Assim, ainda que, atento às essências matemáticas e noções comuns, não se possa duvidar atualmente delas, é possível, desde que não se atente mais para elas, e sim para o objeto obscuro e confuso da hipótese metafísica, colocá-las em dúvida como que retrospectivamente; ou seja, a hipótese do Deus Enganador, justamente por representar obscura e confusamente a causa do ser do ego pensante, é capaz de suspender a irresistível adesão à evidência intelectual a que ele é constrangido por força de sua própria natureza. Entretanto, estamos cientes do desafio que se impõe a essa interpretação, desafio lançado por questões como as seguintes: é possível de direito estabelecer alguma certeza inabalável prescindindo da verdade das noções comuns? É possível de fato um itinerário de pensamento na direção da verdade sob condições nas quais a própria forma a priori do pensar é colocada em dúvida? Não se legitimaria, com isso, a objeção de circularidade, que Descartes mesmo teve que enfrentar? - Sobre a possibilidade da dúvida metafísica, cf. BEYSSADE, 1997, especialmente p. 16-26. Nesse artigo, Beyssade procura responder à objeção de circularidade com base numa interpretação acerca da natureza e das condições do ato de duvidar, interpretação que, em linhas muito gerais, resumimos acima.

12 Note-se, quanto a esse ponto, que essas verdades que é preciso provar metafisicamente, para que seja legitimada a "persuasão natural" da razão pela evidência, não correspondem à clareza e à distinção simplesmente lógicas de um pensamento, mas à existência e à essência reais de uma coisa. Com efeito, em carta a Clerselier de 23/04/1649, Descartes afirma, justamente no contexto da discussão sobre a prova da existência de Deus da Terceira Meditação, que "a verdade não é distinta da coisa verdadeira ou da substância, nem a perfeição da coisa perfeita"; que "a verdade consiste no ser, e a falsidade somente no não-ser” (DESCARTES, 1989, p. 922-923; AT,V, 356). Aqui, verdade aparece como sinônimo de realidade, adjetivando propriedades das coisas: "perfeições verdadeiras e reais", escreve Descartes. Trata-se da verdade como subsistência da coisa. Esse conceito de verdade, se é que podemos qualificá-lo assim, encontra na ordem real das coisas o seu âmbito próprio de aplicação, assim como o de verdade como evidência, se aplica propriamente à ordem lógica dos pensamentos. Desse ponto de vista, a obra de Descartes que melhor responde a tal conceito seriam, ao lado da "Exposição Geométrica" das Segundas Respostas, os Princípios, mais afeitos à "ordem sintética”, à diferença da "ordem analítica” das Meditações. Não por acaso, é nos Princípios, SS 51-54, que encontramos o pequeno tratado de Descartes sobre a substância, considerada como a maneira de ser das coisas em sua existência formal ou eminente, independente do pensamento finito; ou melhor, na medida em que as coisas não dependem de nada, a não ser do concurso divino, para subsistirem como tais (cf. DESCARTES, 2002, p. 67-69, \52).Vale lembrar que, como Marion bem o mostra, a substância é uma categoria renegada pelas Regras.

13 "Desconhecendo-se a origem da natureza humana ou, mais particularmente, desconhecendo-se a natureza da razão, não se sabendo, portanto, se ela é uma faculdade que pode conhecer o verdadeiro, é então legítimo engendrar uma dúvida radical: se é a natureza da razão humana que torna impossível não acreditar que a percepção clara e distinta seja verdadeira, é também uma consideração sobre a natureza da razão que produz um argumento para duvidar da evidência” (LANDIM, 1992, p. 107). 
14 "Há que notar, a esse respeito, que o entendimento nunca pode ser enganado por nenhuma experiência, desde que tenha somente a intuição precisa da coisa que lhe é apresentada, conforme a possua em si mesmo ou numa imagem [...] Somente podemos ser enganados ao compor nós mesmos de certa maneira o que acreditamos. [...] Essa composição pode ser feita de três formas, a saber: por impulso, por conjectura ou por dedução. É por impulso que compõem seus juízos sobre as coisas aqueles cujo espírito inclina a alguma crença, sem que disso sejam persuadidos por nenhuma razão, mas determinados somente, seja por alguma potência superior, seja pela liberdade própria, seja por uma tendência da imaginação: a primeira influência nunca engana, a segunda raramente, a terceira quase sempre; mas a primeira não tem lugar aqui, porque não se ergue a partir da arte" (DESCARTES, 1999, p. 88-89; AT, X, 423-424). Ao nosso ver, o fato de que a possibilidade do engano é, nesse contexto, peremptoriamente descartada atesta a pretensão de fundar o conhecimento objetivo exclusivamente no espírito humano, tido como autônomo, por abstração da natureza isolada das coisas bem como de "alguma potência superior", que, assim, supostamente não desempenharia nenhuma influência, seja benéfica ou nefasta, no conhecimento: pois ela "não se ergue a partir da arte".

15 Cf. carta a Mersenne de 28/01/1641: "Pois jamais tratei do Infinito senão para me submeter a ele, e não para determinar o que ele é ou o que ele não é” (DESCARTES, 1947, p. 265266; AT, III, 292).

16 Validade limitada porque, não bastasse a restrição ao conhecimento puramente intelectual operada pela dúvida metafísica, a veracidade divina se estende, como revela a Sexta Meditação, igualmente à validação das percepções sensíveis, idéias essencialmente obscuras e confusas, como conhecimentos - ao menos em um sentido pragmático - verdadeiros. Cf. DESCARTES, 1994, p. 198; AT, IX-1, 71.

17 Cf. o Axioma V da "Exposição Geométrica": “A realidade objetiva de nossas idéias requer uma causa, em que esta mesma realidade seja contida, não só objetiva, mas também formal, ou eminentemente. E cumpre notar que este axioma deve ser tão necessariamente admitido, que só dele depende o conhecimento de todas as coisas, tanto sensíveis quanto insensíveis. Pois como sabemos, por exemplo, que o céu existe? Será por que o vemos? Mas essa visão não afeta de modo algum o espírito, a não ser na medida em que é uma idéia: uma idéia, digo, inerente ao próprio espírito, e não uma imagem pintada na fantasia; e, por ocasião dessa idéia, não podemos julgar que o céu existe, a não ser que suponhamos que toda idéia deve ter uma causa de sua realidade objetiva que seja realmente existente; causa que julgamos ser o céu mesmo; e assim por diante" (DESCARTES, 1994, p. 239; AT, IX-1, 128).

18 Cf. a densa argumentação do décimo sétimo parágrafo da TerceivaMeditação, ao longo da qual Descartes procura demonstrar que as idéias têm necessariamente como causa de sua realidade objetiva uma realidade formal (DESCARTES, 1994, p. 144-146; AT, IX-1, 32-33).

19 Cf. o Axioma I da "Exposição Geométrica" das Segundas Respostas (DESCARTES, 1994, p. 238; AT, IX-1, 127).

20 "Ela [uma proposição matemática] pode ter toda a clareza geométrica possível; falta-lhe, porém, um elemento de clareza, a clareza metafisica, pois a relação à idéia de verdade e a suas condições, a adequação entre a mente e a coisa, a natureza de meu entendimento, a

doispontos, Curitiba, São Carlos, vol. 5, n. 1, p.43-66, abril, 2008 


\section{4}

dependência da própria ve rdade relativamente a um Deus infinito, não são elementos extrínsecos à percepção clara e distinta. Eles são partes constituintes dela. [...] Enquanto nossa relação com esse ser [o ser infinito e autor de todas as coisas] não for elucidada, resta algo de obscuro e confuso $\mathrm{em}$ todas as nossas percepções, não importa quão claras elas possam ser sob outro ponto de vista” (BEYSSADE, 1997, p. 24).

${ }^{21} \mathrm{Na}$ Quarta Meditação, lemos: "sabendo já que minha natureza é extremamente fraca e limitada, e ao contrário que a de Deus é imensa, incompreensível e infinita [...]" (DESCARTES, 1994, p. 161; AT, IX-1, 44).

22 Com efeito, na TerceiraMeditação, Descartes afirma que "há mais realidade na substância infinita do que na substância finita", de modo que "eu" não poderia conceber "minha" própria existência, uma existência finita, senão por limitação da existência infinita, a de Deus (DESCARTES, 1994, p. 150;AT, IX-1, 36); e, na Quarta Meditação, lemos que "sou como que um meio entre Deus e o nada, isto é, colocado de tal maneira entre o soberano ser e o nãoser" (DESCARTES, 1994, p. 160; AT, IX-1, 43). - A propósito, essas passagens demonstram outro ponto fundamental: que, nas Meditaçoes, o ego pensante encontra-se, para falarmos com Alquié, situado por relação ao ser. Ele se afirma como um existente finito por relação ao infinito, sendo este de início apenas suposto e depois revelado em sua condição de causa primeira, notadamente como causa do ser do ego. Isso é sobremaneira importante, pois, nas Regras, visto que a existência é tomada como uma natureza simples, ou seja, como objeto do pensamento metódico (cf. DESCARTES, 1999, p. 84; AT, X, 419), o espírito humano era considerado como que ontologicamente neutro, impedindo-se com isso a posição da questão sobre o seu ser (finito ou infinito, contingente ou necessário, efeito ou causa, acidente ou substância etc.). Esse ponto, concernente à "situação" ontológica do ego, constitui uma ocasião decisiva para o questionamento da relação entre a epistemologia das Regras e a metafísica das Meditações, pois se poderia mostrar que a neutralidade ontológica do ego era o que, nas Regras, garantia a sua autonomia epistemológica (cf. MARION, 1997, p. 96), condição que lhe será negada nas Meditações, uma vez que, nestas, a possibilidade do conhecimento não só depende da veracidade de Deus como requer incessantemente o seu concurso. Como o tratamento deste tema ultrapassa o objetivo do presente texto, que é o de simplesmente levantar o problema da relação entre método e metafisica na filosofia cartesiana, limitamo-nos por ora a apenas mencioná-lo, muito embora o seu tratamento pudesse contri buir significativamente para a sustentação da tese que procuramos defender. Fica ele para outra ocasião.

${ }^{23}$ Encontramos na Quarta Meditação uma passagem desconcertante a esse respeito:"Pois, por exemplo, se considero a faculdade de conceber que há em mim, acho que ela é de uma extensão muito pequena e grandemente limitada e, ao mesmo tempo, eu me represento a idéia de uma outra faculdade muito mais ampla e mesmo infinita; e, pelo simples fato de que me posso representar sua idéia, conheço sem dificuldade que ela pertence à natureza de Deus” (DESCARTES, 1994, p. 163; AT, IX-1, 45). Um leitor poderia perguntar: mas por qual faculdade são representadas a idéia do entendimento infinito e, pelo mesmo meio, a do entendimento finito senão pelo próprio entendimento, no caso, um entendimento finito? Ou será que a capacidade de representar idéias não é exclusiva do entendimento, como parece indicar o caso excepcional da idéia do infinito? Atento a esse problema, o de "legitimar a introdução do infinito nas operações do Eu penso", Vuillemin reconhece nisso um "conflito insuportável à razão": "Ou bem se a colocará [a idéia do infinito] na conta de uma 
faculdade obscura, extrínseca ao entendimento [...] ou bem se deverá atribuir ao entendimento mesmo uma faculdade incompatível com os critérios rigorosos da luz natural" (VUILLEMIN, 1987, p. 140).

24 Quanto a esse ponto, o contraste com a filosofia transcendental de Kant é bastante frutífero: como se sabe, no uso teórico da razão, a idéia de sistema coincide com a idéia, absolutamente carente de realidade objetiva, de Deus. Visto que a sistematicidade só pode ser garantida uma vez que o conhecimento teórico se encontre limitado à experiência possível, tese que de certo modo já se encontra formulada nas Regras, ter-se-ia motivo para sustentar que o sistema, necessariamente autônomo, dos conhecimentos racionais se pode constituir apenas a partir do reconhecimento da impossibilidade do conhecimento da existência de Deus, já que este, transcendendo os limites da experiência, implicaria uma espécie de heteronomia da razão em seu uso teórico, arruinando-se com isso a possibilidade do conhecimento a priori. Cf. KANT, 2001, p. 171-172; B 167-168.

25 Assim, nossa conclusão não consiste senão numa glosa da tese de Philonenko segundo a qual "o grande problema do cartesianismo é o conflito entre o método e a metafísica" (PHILONENKO, 1990, p. 12).

\section{Referências bibliográficas}

ALQUIÉ, F. 2000. La découverte métaphysique de l'homme chez Descartes. 6a. ed. Paris: Presses Universitaires de France.

BEYSSADE, J.-M. 1997. Sobre o círculo cartesiano. Analytica, Rio de Janeiro, vol. 2, no. 1, p. 11-36.

. 2001. Ordre et mesure: Descartes aux limites de la raison. In:

Descartes au fil de l'ordre. Paris: Presses Universitaires de France.

DESCARTES, R. 1947. Correspondance, t. IV. Publiée avec une introduction et des notes par Ch. Adam et G. Milhaud. Paris: Presses Universitaires de France.

1986. Oeuvres, vol. X. Publiées par Charles Adam \& Paul Tannery. Paris:Vrin.

. 1989. OEuvres philosophiques, t. III. Textes établis, présentés et annotés par Ferdinand Alquié. Paris: Bordas.

1992. Méditations métaphysiques. Présentation par Michelle et Jean-Marie Beyssade. Paris: Flammarion. [Texto em latim e em francês.] 
1994. Obra escolhida. Trad. J. Guinsburg e Bento Prado Júnior. $3^{a}$. ed. Rio de Janeiro: Bertrand Brasil. 1999. Regras para a orientação do espírito. Tradução de Maria Ermantina Galvão. São Paulo: Martins Fontes. . 2002. Princípios da filosofia. Trad. Guido Antônio de Almeida (coord.) Rio de Janeiro: Editora UFRJ.

GUEROULT, M. 1968. Descartes selon l'ordre des raisons, t. I: L'âme et Dieu. 2a. ed. Paris: Aubier.

HEIDEGGER, M. 1992. O que é uma coisa? Trad. Carlos Morujão. Lisboa: Edições 70.

HUSSERL, E. 2001. Meditações cartesianas. Trad. Frank de Oliveira. São Paulo: Madras.

KANT, I. 2001. Crítica da razão pura. Trad. Manuela Pinto dos Santos e Alexandre Fradique Morujão. 5a. ed. Lisboa: Calouste Gulbenkian.

LANDIM, R. 1992. Evidência e verdade no sistema cartesiano. São Paulo: Edições Loyola.

MARION, J.-L. 1996. La "règle générale" de vérité. In: Questions cartésiennes II. Paris: Presses Universitaires de France. 1997. Sobre a ontologia cinzenta de Descartes. Trad. Armando Pereira de Silva e Teresa Cardoso. Lisboa: Instituto Piaget.

PHILONENKO, A. 1990. De la présupposition chez Descartes et Fichte. In: Le transcendantal et la pensée moderne. Paris: Presses Universitaires de France.

VILLORO, L. 1965. La idea y el ente en la filosofía de Descartes. México : Fondo de Cultura Económica.

VUILLEMIN, J. 1987. Mathématiques et métaphysique chez Descartes. 2a. ed. Paris: Presses Universitaires de France. 